\title{
Rancang Bangun Alat Pointing Antena VSAT Berbasis Mikrokontroler
}

\author{
Imam MPB $^{1}$, Eka Wahyudi ${ }^{2}$, Fajar Aristiyanto ${ }^{3}$ \\ 1,2,3 Sekolah Tinggi Teknologi Telematika Telkom Purwokerto \\ 1,2,3 JL. DI Panjaitan No. 128 Purwokerto 53147 Indonesia \\ Email Korespondensi: imam@st3telkom.ac.id
}

Dikirim 14 Maret 2016, Diperbaiki 23 Maret 2016, Diterima 29 Maret 2016

\begin{abstract}
Abstrak - Penelitian ini membahas salah satu aplikasi mikrokontroler Atmega16 yang digunakan sebagai media pointing antena VSAT. Untuk menentukan sudut azimuth dan elevasi, menggunakan perubahan linier dari potensiometer yang terhubung dengan mikrokontroler digunakan sebagai sensor sudut dalam menentukan sudut azimuth dan elevasi. Untuk menentukan sudut tersebut mikrokontroler memanfaatkan fitur ADC internal sebagai konversi dari analog menjadi digital berdasarkan perubahan linier potensiometer. Tujuan utama dari penelitian ini ialah dapat membandingkan hasil yang diperoleh dari pointing manual dan otomatis dengan memanfatkan potensiometer sebagai sensor sudut, parameter yang diguakan sebagai acuan dari hasil pointing alat ini adalah signal strength, signal quality, BER dan C/N. Dari hasil pengujian pointing pada dua satelit yang berbeda didapat kesimpulan bahwa perbandingan hasil pointing manual lebih baik dari pada hasil pointing elektronik dari segi signal strength dan Signal Quality. Sedangkan perbedaan nilai BER dan $C / N$ tidak terlalu besar, bahkan cenderung sama. Nilai total rata-rata dari hasil pointing manual untuk satelit TELKOM 1 adalah signal strength $37 \%$, Signal Quality $56 \%$, BER $10^{-5}, \mathrm{C} / \mathrm{N} 8 \mathrm{~dB}$ dan pointing elektronik dengan nilai rata-rata total yaitu signal strength $36 \%$, Signal Quality 55,4\%, BER $10^{-5}$ dan $C / N 7,9 \mathrm{~dB}$. Untuk hasil rata-rata total pointing satelit PALAPA D yaitu signal strength 43,5\%, Signal Quality 59,5\%, BER $10^{-5}$, C/N 8,5dB dan pointing elektronik dengan nilai rata-rata total yaitu signal strength $36 \%$, Signal Quality 40,9\%, BER $10^{-5}$ dan C/N 8,5dB. Meski demikian alat ini dapat bekerja lebih sempurna apabila ditambahkan sensor yang memliki tingkat akurasi lebih baik.
\end{abstract}

Kata Kunci - Analog to Digital Converter (ADC) Channel, BER, C/N, signal strenght, signal quality.

\begin{abstract}
In this research, we discuss an application of microcontroller Atmegal6 which is used as a pointing media for VSAT antenna. We use a linear change of potentiometer to choose azimuth and elevation angle. The potentiometer which connected with microcontoller are used as angle sensors to determine the azimuth and elevation angle. The ADC internal is used to convert an analog linear change of potentiometer into digital form. The main purpose of this research is to compare the electrical parameter of antenna as a result of manual and electronic pointing. Parameters used as reference for result of these pointing device are signal strength, signal quality, BER and C/N. The experimental result using two difference satellite target, we have shown the manual pointing better than the electronic pointing to get signal strength and quality, while the BER and C/N value are almost similar. Using the manual pointing and Satellite Telkom 1 as a target, the average value of electrical parameter of antenna are signal strength of $37 \%$, signal quality of $56 \%, B E R$ of $10^{-5}$, C/N of $8 d B$, while using the electronic pointing, the average value of electrical parameter of antenna are signal strength of $36 \%$, signal quality of $55.4 \%, B E R$ of $10^{-5}$, C/N of 7.9dB. Using the manual pointing and Satellite PALAPA D as a target, the average value of electrical parameter of antenna are signal strength of $43.5 \%$, signal quality of $59.5 \%$, BER of $10^{-5}$, C/N of $8.5 \mathrm{~dB}$, while using the electronic pointing, the average value of electrical parameter of antenna are signal strength of $36 \%$, signal quality of $40.9 \%$, BER of $10^{-5}$, C/N of $8.5 \mathrm{~dB}$.
\end{abstract}

Keywords - Analog To Digital Converter (ADC) Channel, BER, C/N, signal strenght, signal quality

\section{PENDAHULUAN}

Pointing antena parabola adalah cara yang dilakukan untuk mendapatkan sinyal yang dikirimkan oleh satelit dengan mengatur sudut elevasi dan azimuth pada antena stasiun bumi [1]. Proses pointing yang diset dan digerakkan secara elektronik, (pointing elektronik), tentunya akan mempermudah dan mempercepat hasil pointing, yaitu dengan memasang suatu alat, dimana alat tersebut berfungsi untuk menggerakkan parabola sesuai dengan sudut azimuth dan elevasinya. Pengendali alat tersebut dapat berupa komputer atau mikrokontroler.

Pointing antena secara manual dan elektronik pasti memiliki kelebihan dan kekurangan. Pointing 
antena parabola secara manual memiliki kelebihan diantaranya antena akan tetap kokoh atau tidak goyang setelah dilakukan pointing, serta signal quality dapat maksimum. Namun pointing manual juga memiliki kelemahan yaitu waktu yang dibutuhkan untuk pointing lama, dan membutuhkan lebih dari satu LNB (Low Noise Block) apabila akan digunakan untuk menangkap lebih dari satu satelit. Karena jika hanya menggunakan satu LNB sinyal channel yang didapatkan sedikit. Pointing elektronik antena parabola menjadi mudah dan cepat, dapat menggunakan satu LNB apabila digunakan untuk menangkap lebih dari satu satelit transmitter, sehingga channel yang diperoleh lebih banyak, akan tetapi pointing ini memiliki kelemahan yaitu posisi dapat berubah karena sistem mekanik yang kurang sempurna dan mengakibatkan kurang maksimalnya signal quality yang dihasilkan. Dalam proses pointing elektronik ini, pengguna cukup mengatur sudut azimuth dan elevasi yang diinginkan melalui alat, dan alat akan mengeksekusi perintah yang diberikan.

Untuk menciptakan alat tersebut perlu dilakukan perancangan. Di dalam perancangan alat ini, proses pergerakan antena akan diatur oleh mikrokontroler yang telah diprogram dan mengunakan potensiometer sebagai sensor sudut untuk menentukan berapa besarnya sudut yang akan dituju dan menentukan pergerakan antena. Sensor tersebut terhubung dengan ADC pada mikrokontroler untuk melakukan proses tersebut. Pergerakan putaran antena dalam melakukan proses pointing dilakukan dengan memasang dua buah motor DC, motor DC pertama digunakan sebagai pergerakan azimuth dan motor DC kedua sebagai pergerakan elevasi. Untuk menggerakkan motor perlu ditambahkan rangkaian driver relay, rangkaian ini berfungsi sebagai saklar elektronik dimana saklar ini akan bekerja apabila mikrokontroler memberikan logika $1 / 0$ pada driver relay tersebut. Pada saat driver relay diberikan logika ' 1 ', relay akan mengalirkan arus untuk memutar motor DC dan apabila driver relay diberi logika ' 0 ' maka relay akan memutus arus yang mengalir ke motor DC. Input dari mikrokontroler yaitu keypad matrix yang terhubung ke mikrokontroler yang digunakan sebagai media untuk memasukkan data ke dalam mikrokontroler.

Dari pembahasan diatas permasalahan yang dihadapi yaitu bagaimana cara merancang dan membangun suatu alat bersistem mikrokontroler agar dapat digunakan utuk membantu mempermudah pointing antena parabola. Hasil dari pointing elektronik antena parabola dibandingkan dengan hasil pointing secara manual dengan membandingkan nilai parameter BER, C/N, Sinyal strenght, dan sinyal quality [5]. Hasil yang diharapkan ialah nilai parameter yang dihasilkan lebih baik atau nilainya sama.

\section{METODOLOGI PENELITIAN}

Pada sistem komunikasi satelit penempatan stasiun bumi harus pada posisi yang tepat dan berada pada daerah cakupan satelit agar sinyal yang dikirim dapat diterima satelit dan dipancarkan kembali ke stasiun bumi pada posisi yang tepat [1]. Agar dapat berkomunikasi dengan satelit harus diketahui sudut azimuth dan elevasi agar daya yang dipancarkan atau diterima dapat optimal. Sudut elevasi merupakan sudut yang dihasilkan oleh arah utara sebenarnya dari titik yang dipasang antena dengan arah vertical antena terhadap satelit. Sedangkan sudut azimuth merupakan sudut putar pada arah horizontal, dimana arah utara digunakan sebagai referensi sudut (0) [1][2].

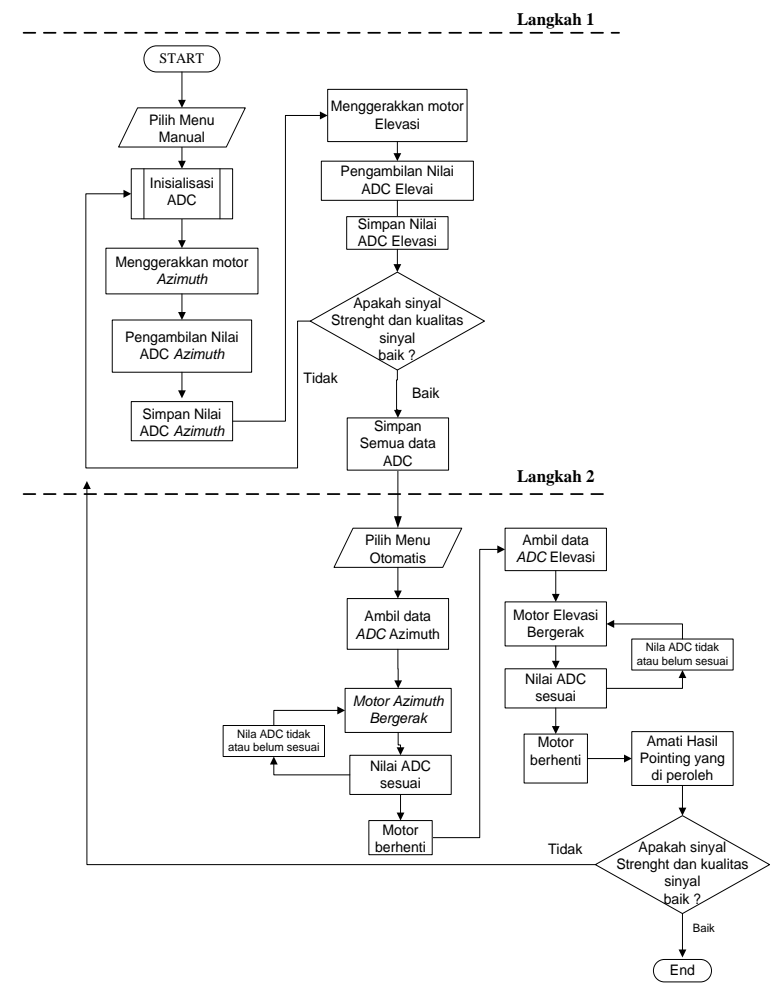

Gambar 1. Proses Kerja Alat Pointing Antena

Berikut adalah cara untuk melakukan perhitungan mencari sudut azimuth [1][2].

1. Sebelah Utara Khatulistiwa

a. Stasiun bumi berada di barat satelit . $\mathrm{A}=180^{\circ}-\mathrm{A}^{\prime}$

b. Stasiun bumi berada di timur satelit. $\mathrm{A}=180^{\circ}+\mathrm{A}^{\prime}$

2. Sebelah Selatan Khatulistiwa

a. Stasiun bumi berada di barat satelit. $A=A^{\prime}$

b. Stasiun bumi berada di timur satelit. $\mathrm{A}=360^{\circ}-\mathrm{A}^{\prime}$

Dengan A' merupakan sudut positif, untuk mancari nilai A' dapat menggunakan persamaan (5).

$A^{\prime}=\tan ^{-1}\left[\frac{\tan \mid \text { longSB-longSat } \mid}{\sin \text { latSB }}\right]$

Dengan 


$$
\begin{array}{ll}
\text { longSB } & =\text { Longitude Stasiun Bumi }\left(^{\circ}\right) \\
\text { longSat } & =\text { Longitude Satelit }\left(^{\circ}\right) \\
\text { latSB } & =\text { Latitude Stasiun Bumi }\left(^{\circ}\right)
\end{array}
$$

Besarnya nilai sudut elevasi dapat dihitung menggunakan persamaan (6) [2].

$$
\begin{aligned}
& E \tan ^{-1}\left[\frac{(\cos l \cdot \cos L)-0,151}{\sqrt{1-(\cos l \cdot \cos L)^{2}}}\right] \\
& \begin{aligned}
\text { Dengan } & \text { Sudut Elevasi }\left(^{\circ}\right) \\
\mathrm{E}= & \text { Latitude stasiun bumi }\left(^{\circ}\right) \\
\text { Cosl } & \text { selisih longitude stasiun bumi } \\
\text { CosL } & \text { dengan satelit }\left(^{\circ}\right)
\end{aligned}
\end{aligned}
$$

III. PERANCANGAN DAN PRINSIP KERJA ALAT

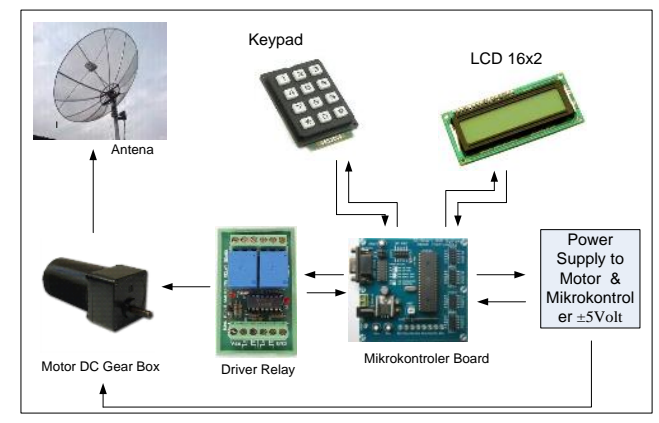

Gambar 2. Diagram Perancangan Alat

Dalam perancangan alat pada Gambar 2, mikrokontroler digunakan sebagai pusat pengendali utama untuk memberikan perintah kepada motor untuk menggerakkan antena. Keypad digunakan untuk memberikan input sudut dan relay digunakan sebagai saklar elektronik untuk motor.

\section{A. Modul Mikrokontroler}

Modul mikrokontroler berfungsi untuk memberi perintah kepada motor untuk bergerak. Modul ini terdiri dari $L C D$ yang digunakan sebagai tampilan pada modul pada saat memberikan perintah dari keypad dan juga output untuk motor $D C$.

Mikrokontroler yang digunakan yaitu ATMEGA16, dalam mikrokontroler ini terdapat 40 pin dan terbagi menjadi beberapa port yaitu port A, port $\mathrm{B}$, port $\mathrm{C}$ dan port $\mathrm{D}$, masing-masing pin diberikan sesuai dengan kebutuhan kerjanya. Susunan pin mikrokontroler ATMEGA16 ditunjukkan pada Gambar 3 [6].

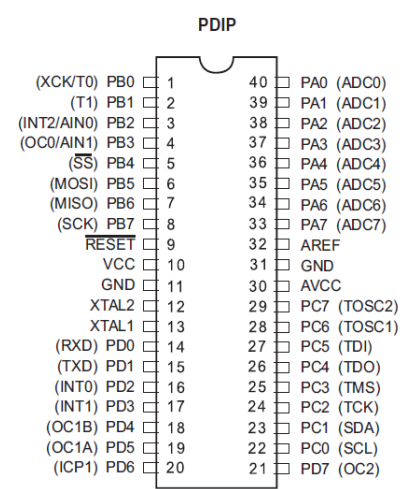

Gambar 3. Susunan Pin ATMEGA 16 [6]
Pin yang digunakan pada perancangan alat ini ditunjukkan pada Tabel 1 sampai Tabel 4.

Tabel 1. Pin Mikrokontroler Untuk Koneksi LCD

\begin{tabular}{cc}
\hline PIN & LCD \\
\hline PC. 0 & RS \\
PC. 1 & R/W \\
PC. 2 & E \\
PC. 3 & - \\
PC. 4 & D4 \\
PC. 5 & D5 \\
PC. 6 & D6 \\
PC. 7 & D7 \\
\hline
\end{tabular}

Tabel 2. Pin Mikrokontroler Output Driver Relay Untuk Motor

\begin{tabular}{cc} 
& $D C$ \\
\hline PIN & Driver Relay \\
\hline PB.0 & Motor Azimuth \\
PB.1 & Motor Azimuth \\
PB.2 & Motor Elevasi \\
PB. 3 & Motor Elevasi \\
\hline
\end{tabular}

Tabel 3. Pin Mikrokontroler Sebagai Koneksi Keypad

\begin{tabular}{cc}
\hline PIN & KEYPAD \\
\hline PD.0 & ROW 1 \\
PD.1 & ROW 2 \\
PD.2 & ROW 3 \\
PD.3 & ROW 4 \\
PD.4 & - \\
PD.5 & COL 1 \\
PD.6 & COL 2 \\
PD.7 & COL 3 \\
\hline
\end{tabular}

Tabel 4. Pin $A D C$ Mikrokontroler

\begin{tabular}{cc}
\hline PIN & ADC \\
\hline PA.6 & $A D C$ motor Azimuth \\
PA.7 & $A D C$ motor Elevasi \\
\hline
\end{tabular}

\section{B. Rangkaian Driver Relay}

Rangkaian driver transistor dan relay merupakan rangkaian untuk mengaktifkan relay. Rangkaian ini mendapat sumber daya dari adaptor sebesar 12 Volt dan 36 Volt, tegangan tersebut digunakan untuk menggerakkan motor DC Azimuth 12 Volt dan motor DC elevasi 36 Volt. Kondisi Swiching Relay ditunjukkan pada Gambar 4 [10].

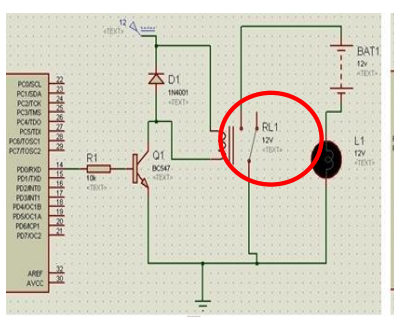

(a) saklar terhubung

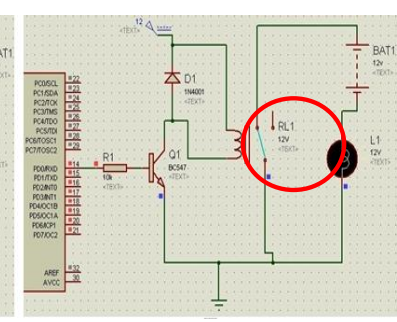

(b) saklar terbuka
Gambar 4. Kondisi Swiching Relay 
Ketika transistor mendapatkan tegangan/arus pada basisnya maka arus akan mengalir dari collector ke emitter. Dengan saturasinya transistor maka arus mengalir dari power supply menuju ground melalui magnet coil dan menyebabkan relay dalam keadaan aktif (saklar terhubung). Sebaliknya jika basis tidak mendapat tegangan dari mikrokontroler maka transistor cut-off dan tidak ada arus mengalir melalui magnet coil, menyebabkan saklar terbuka. Rangkaian relay yang digunakan pada perancangan alat ditunjukkan pada Gambar 5 [7].

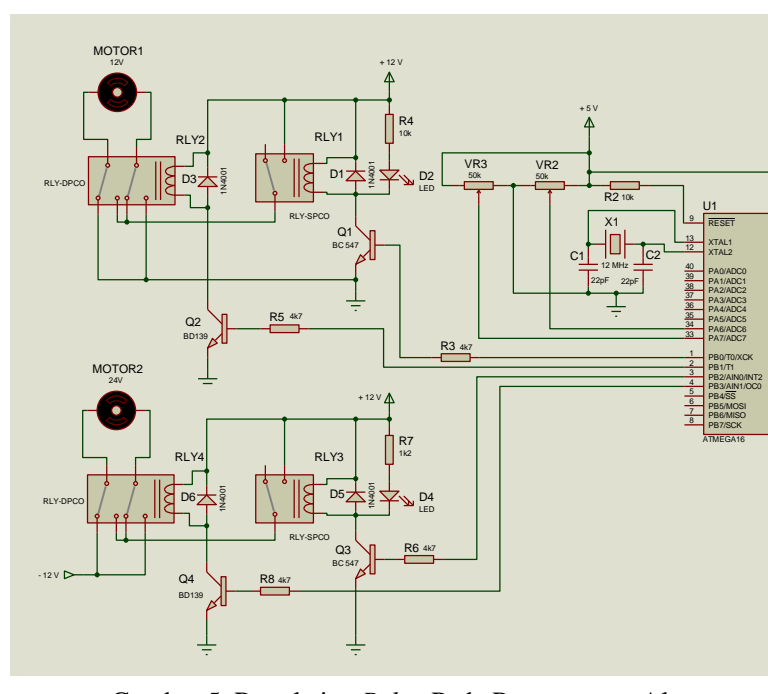

Gambar 5. Rangkaian Relay Pada Perancangan Alat

\section{Cara Kerja Keypad}

Agar mikrokontroler dapat membaca tombol keypad perlu dilakukan scanning, dimana baris dan kolom selalu dipindai agar mendeteksi tombol yang ditekan yaitu dengan cara memberikan logika ' 0 ' (low) atau ' 1 ' (high) pada pin column atau pin row.
Konfigurasi keypad pada mikrokontroler ditunjukkan pada Gambar 6.

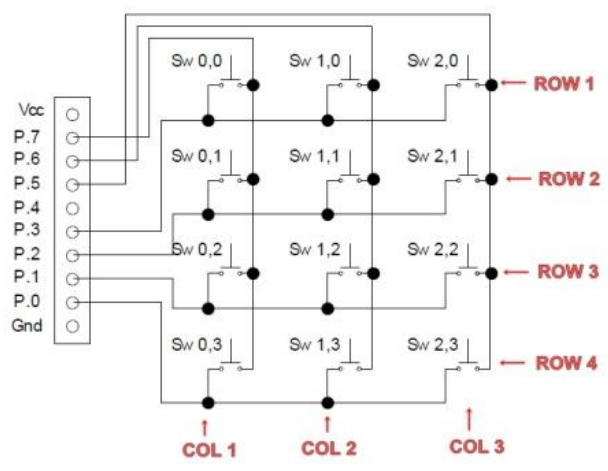

Gambar 6 Konfigurasi Keypad dan Mikrokontroler

Ketika keypad tidak ditekan maka kondisi Row 1 , 2, 2, 4 berlogika ' 1 ' dan begitu pula kondisi pada $\mathrm{Col}$ 1, 2, 3 berlogika ' 1 '. Namun ketika menekan angka maka salah satu pin akan berlogika ' 0 '. Proses scanning pada mikrokontroler ditunjukkan pada Tabel 5.

\section{Cara Kerja Motor DC dan Antena}

Motor DC berfungsi sebagai penggerak azimuth dan elevasi antena, pergerakan antena berdasarkan sudut yang dimasukkan. Untuk menuju sudut yang dituju power supply akan memberikan arus dan tegangan selama waktu yang ditentukan dengan memanfaatkan driver relay. Waktu yang ditentukan yaitu lamanya waktu motor dalam keadaan $0^{\circ}$ sampai dengan sudut yang dituju, misalkan $350^{\circ}$. Perubahan sudut antenna ditunjukkan pada Gambar 7 dan 8.

Tabel 5. Proses Scaning Mikrokontroler Pada Keypad Matrix 3x4

\begin{tabular}{cccccccccc}
\hline \multicolumn{2}{l}{ Tombol } & P.0 & P.1 & P.2 & P.3 & P.4 & P.5 & P.6 & P.7 \\
\hline 1 & Sw 0,0 & 1 & 1 & 1 & 0 & - & 1 & 1 & 0 \\
2 & Sw 1,0 & 1 & 1 & 1 & 0 & 1 & 1 & 0 & 1 \\
3 & Sw 2,0 & 1 & 1 & 1 & 0 & 1 & 0 & 1 & 1 \\
4 & Sw 0,1 & 1 & 1 & 0 & 1 & 1 & 1 & 1 & 0 \\
5 & Sw 1,1 & 1 & 1 & 0 & 1 & 1 & 1 & 0 & 1 \\
6 & Sw 2,1 & 1 & 1 & 0 & 1 & 1 & 0 & 1 & 1 \\
7 & Sw 0,2 & 1 & 0 & 1 & 1 & 1 & 1 & 1 & 0 \\
8 & Sw 1,2 & 1 & 0 & 1 & 1 & 1 & 1 & 0 & 1 \\
9 & Sw 2,2 & 1 & 0 & 1 & 1 & 1 & 0 & 1 & 1 \\
0 & Sw 0,3 & 0 & 1 & 1 & 1 & 1 & 1 & 0 & 1 \\
$*$ & Sw 1,3 & 0 & 1 & 1 & 1 & 1 & 1 & 1 & 0 \\
$\#$ & Sw 2,3 & 0 & 1 & 1 & 1 & 1 & 0 & 1 & 1 \\
\hline
\end{tabular}



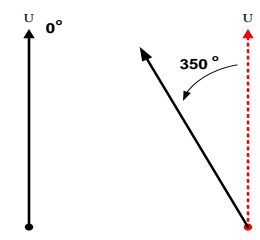

(a) Perubahan sudut Azimuth

Gambar 7. Perubahan Sudut Antena Satelit Telkom [3]

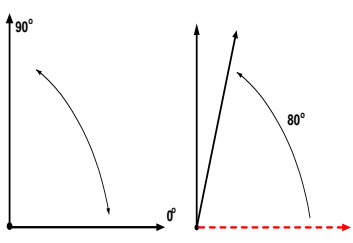

(b) Perubahn sudut elevasi

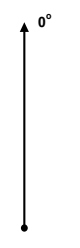

(a) Perubahan sudut
Azimuth

Gambar 8. Perubahan Sudut Antena Satelit Palapa D [3]

\section{E. Menentukan Besarnya Sudut}

Alat ini menggunakan potensiometer jenis karbon dengan perubahan tahanan bersifat linier sebagai sensor pengukur besar sudut (derajat). Perubahan tahanan pada potensiometer akan mengakibatkan perubahan tegangan masukan ADC sesuai dengan perubahan tahanan potensiometer.

Sudut Untuk Satelit TELKOM 1

Azimuth: $350^{\circ}$

$$
\begin{aligned}
& \text { Vin } 350^{\circ}=\frac{350}{270} \times 5=6,4814 \text { volt } \\
& A D C=\frac{\operatorname{Vin} \times 1024}{5}=1327.390 \\
& A=\left(\frac{1024-A D C}{1024} \times 270\right)-270 \\
& A=\left(\frac{1024-1327,390}{1024} \times 270\right)-270 \\
& A=-350^{\circ} \\
& A=350^{\circ}
\end{aligned}
$$

Elevasi: $80^{\circ}$

$$
\begin{aligned}
& \text { Vin } 80^{\circ}=\frac{80}{270} \times 5=1,4814 \text { volt } \\
& \begin{array}{l}
A D C=\frac{\operatorname{Vin} x 1024}{5}=303,390 \\
A=\left(\frac{1024-A D C}{1024} \times 270\right)-270 \\
A=\left(\frac{1024-303,390}{1024} \times 270\right)-270 \\
A=79,995^{\circ} \\
A=80^{\circ}
\end{array}
\end{aligned}
$$

Sudut Untuk Satelit PALAPA D Azimuth: $26^{\circ}$

$$
\begin{aligned}
& \operatorname{Vin} 26^{\circ}=\frac{26}{270} \times 5=0,4814 \text { volt } \\
& A D C=\frac{\operatorname{vin} x 1024}{5}=98,5907 \\
& A=\left(\frac{1024-w}{1024} \times 270\right)-270
\end{aligned}
$$

$$
\begin{aligned}
& A=\left(\frac{1024-98,5904}{1024} \times 270\right)-270 \\
& A=-25,9955^{\circ} \\
& A=26^{\circ} \\
& \text { Elevasi: } 80^{\circ} \\
& \text { Vin } 80^{\circ}=\frac{80}{270} \times 5=1,4814 \text { volt } \\
& A D C=\frac{\text { vin } \times 1024}{5}=303,390 \\
& A=\left(\frac{1024-w}{1024} \times 270\right)-270 \\
& A=\left(\frac{1024-303,390}{1024} \times 270\right)-270 \\
& A=79,995^{\circ} \\
& A=80^{\circ}
\end{aligned}
$$

\section{HASIL PENELITIAN}

Pengujian dilakukan untuk mendapatkan hasil dari pembuatan alat apakah alat bekerja dengan baik atau tidak dengan mengukur dan membandingkan parameter parameter hasil pointing secara manual dan secara elektronik

\section{A. Pengujian Perubahan Sudut}

Pengujian ini bertujuan untuk mengetahui kinerja dan hasil dari pembuatan alat. Dari pengujian alat ini dipaparkan perbandingan hasil dari pointing manual dan pointing elektronik. Pengujian dilakukan sebanyak 5 kali agar mengetahui berapa besar perbedaan yang terjadi dari setiap hasil pengujian untuk mendapatkan nilai rata-rata. Nilai tersebut ditunjukkan pada Tabel 6.

\begin{tabular}{ccccc}
\multicolumn{5}{c}{ Tabel 6. Pengujian Perubahan Sudut Azimuth } \\
\hline $\begin{array}{c}\text { Sudut } \\
\text { awal }\end{array}$ & $\begin{array}{c}\text { Sudut } \\
\text { akhir }\end{array}$ & Manual & $\begin{array}{c}\text { Rerata } \\
\text { perubahan } \\
\text { sudut pointing } \\
\text { elektronik }\end{array}$ & $\begin{array}{c}\text { Rata rata } \\
\text { Error }(\%)\end{array}$ \\
\hline $0^{\circ}$ & $10^{\circ}$ & $10^{\circ}$ & $10.6^{\circ}$ & $6 \%$ \\
$0^{\circ}$ & $20^{\circ}$ & $20^{\circ}$ & $20.6^{\circ}$ & $6 \%$ \\
$0^{\circ}$ & $30^{\circ}$ & $30^{\circ}$ & $30.6^{\circ}$ & $6 \%$ \\
$0^{\circ}$ & $40^{\circ}$ & $40^{\circ}$ & $40.4^{\circ}$ & $4 \%$ \\
$0^{\circ}$ & $50^{\circ}$ & $50^{\circ}$ & 50.2 & $2 \%$ \\
\hline
\end{tabular}

Pada pengujian perubahan sudut elevasi, sudut yang diukur yaitu antara $55^{\circ}$ sampai dengan 85 . Pengukuran tidak dilakukan dari $0^{\circ}$ dikarenakan karateristik dari perangkat yang digunakan. Sama seperti pengujian sebelumnya, pengujian dilakukan sebanyak lima kali dengan range sudut pengujian sebesar $10^{\circ}$ agar mengetahui berapa besar kesalahah yang terjadi. Dari pengujian yang dilakukan dari sudut elevasi $55^{\circ}$ ke $65^{\circ}, 55^{\circ}$ ke $75^{\circ}, 55^{\circ}$ ke $85^{\circ}$ tidak tejadi kesalahan sehingga perubahan sudut elevasi pada alat ini tidak mengalami masalah. Perubahan sudut elevasi ditunjukkan pada Tabel 7 dibawah ini. 
Tabel 7. Pengujian Perubahan Sudut Elevasi

\begin{tabular}{ccccc}
\hline $\begin{array}{c}\text { Sudut } \\
\text { awal }\end{array}$ & $\begin{array}{c}\text { Sudut } \\
\text { akhir }\end{array}$ & Manual & $\begin{array}{c}\text { Rerata } \\
\text { perubahan } \\
\text { sudut } \\
\text { pointing } \\
\text { elektronik }\end{array}$ & $\begin{array}{c}\text { Error } \\
(\%)\end{array}$ \\
\hline $55^{\circ}$ & $65^{\circ}$ & $10^{\circ}$ & $10^{\circ}$ & 0 \\
$55^{\circ}$ & $75^{\circ}$ & $20^{\circ}$ & $20^{\circ}$ & 0 \\
$55^{\circ}$ & $85^{\circ}$ & $30^{\circ}$ & $30^{\circ}$ & 0 \\
\hline
\end{tabular}

\section{B. Pengujian pointing satelit Telkom 1}

Pengujian ini bertujuan mengamati perbandingan hasil dari pointing manual dan menggunakan alat. Prosedur yang digunakan yaitu melakukan pointing sebanyak lima kali baik itu pointing manual ataupun elektronik, dan nilai parameter hasil pointing akan diambil nilai rata-rata nya. Nilai rata-rata dari kedua metode pointing tersebut ditunjukkan pada Tabel 8 dan digambarkan dalam bentuk grafik pada Gambar 9

Tabel 8. Nilai Rata-Rata Kedua Metode Pointing

\begin{tabular}{|c|c|c|c|c|}
\hline Pengujian & $\begin{array}{c}\text { Strength } \\
(\boldsymbol{\%})\end{array}$ & $\begin{array}{c}\text { Quality } \\
(\boldsymbol{\%})\end{array}$ & $\mathbf{B E R}$ & $\begin{array}{c}\text { C/N } \\
(\mathbf{d B})\end{array}$ \\
\hline Manual & 43.5 & 59.5 & $10^{-5.5}$ & 8.5 \\
\hline Otomatis & 40.9 & 59.9 & $10^{-5.2}$ & 8.5 \\
\hline
\end{tabular}

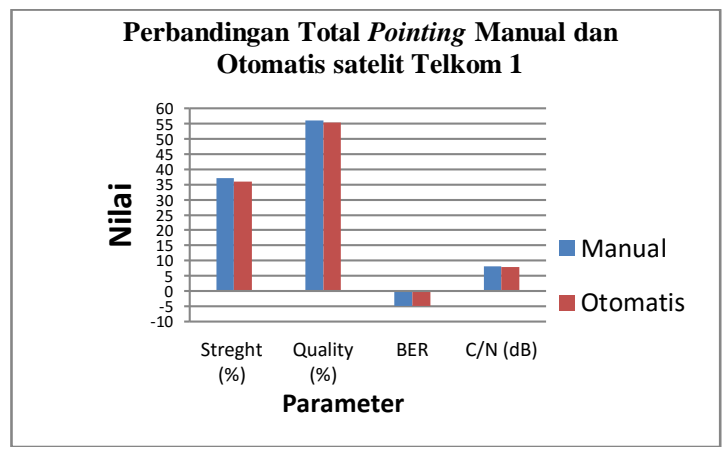

Gambar 9. Grafik total rata-rata perbandingan pointing manual dan otomatis satelit Telkom 1.

\section{Pengujian parameter terukur dari Satelit Palapa \\ $D$}

Sama seperti pada pengujian satelit Telkom 1 pengujian ini bertujuan mengamati perbandingan hasil dari pointing manual dan elektronik. Prosedur yang digunakan yaitu melakukan pointing sebanyak lima kali baik itu pointing manual ataupun elektronik, dan nilai parameter hasil pointing akan dirata-rata. Nilai rata-rata dari kedua metode pointing tersebut dipaparkan pada Gambar 10.

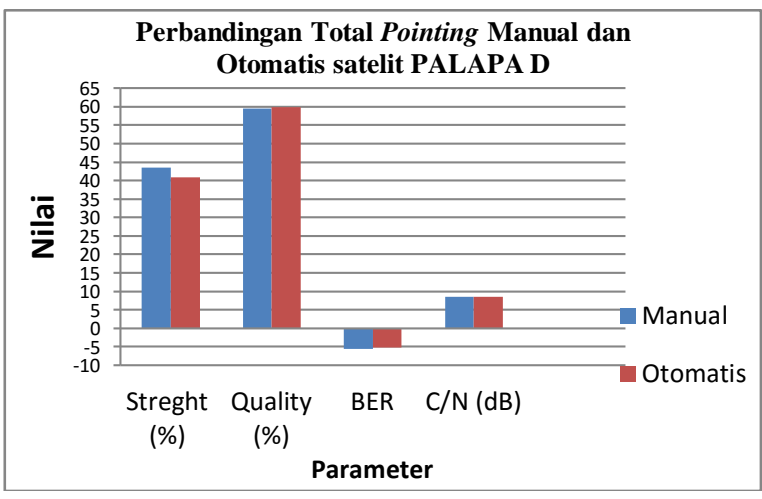

Gambar 10. Grafik total rata-rata perbandingan pointing manual dan elektronik satelit PALAPA D.

\section{PEMBAHASAN}

Parameter yang diukur untuk menunjukkan unjuk kerja alat yang dibuat ialah nilai BER, C/N, Signal strength dan Signal Quality. Hasil tersebut dilihat dari hasil satelit meter pada saat melakukan pointing. Hasil yang diperoleh dari pengujian keseluruhan menunjukkan perbandingan antara pointing manual dan pointing elektronik.

Pada Pengujian parameter terukur dari Satelit Telkom 1 nilai rata-rata total pointing manual yaitu signal strength 37\%, Signal Quality 56\%, BER $10^{-5}$, $C / N 8 \mathrm{~dB}$ dan pointing elektronik dengan nilai ratarata total yaitu signal strength $36 \%$, Signal Quality $55,4 \%, B E R 10^{-4,9}$ dan $C / N 7,9 \mathrm{~dB}$ (pembulatan).

Pada pointing satelit Palapa $\mathrm{D}$, nilai rata-rata total pointing manual yaitu signal strength 43,5\%, Signal Quality 59,5\%, BER $10^{-5,5}$, C/N 8,5 dB. Pointing elektronik dengan nilai rata-rata total yaitu signal strength 36\%, Signal Quality 40,9\%, BER $10^{-5,2}$ dan $C / N$ 8,5dB (pembulatan). Maka dapat disimpulkan bahwa pointing manual lebih unggul dari pada pointing elektronik dari segi signal strength dan Signal Quality.

Untuk mendapatkan hasil yang maksimal dari perancangan ini diperlukan feedback dari satelit sebagai pengontrol alat pada stasiun bumi yaitu dengan cara memberikan interupsi apabila nilai signal quality dari pointing belum mendapatkan hasil yang maksimal maka alat akan tetap bekerja atau dengan kata lain antena akan tetap melakukan pointing sampai mendapatkan hasil yang maksimal. Hal ini dilakukan untuk mengurangi kasalahan pada saat melakukan pointing.

\section{PENUTUP}

\section{A. Kesimpulan}

Berdasarkan penelitian yang dilakukan dapat diambil kesimpulan.

1. Setelah melakukan pengujian alat dalam melakukan pointing terhadap satelit Telkom 1, nilai rata-rata total pointing manual yaitu signal 
strength 37\%, Signal Quality 56\%, BER $10^{-5}$, C/N $8 \mathrm{~dB}$ dan pointing elektronik dengan nilai rata-rata total yaitu signal strength $36 \%$, Signal Quality $55,4 \%, B E R 10^{-4,9}$ dan $C / N 7,9 \mathrm{~dB}$. Maka dapat disimpulkan bahwa pointing manual lebih unggul dari pada pointing elektronik dari segi signal strength dan Signal Quality. Sedangkan nilai BER dan $C / N$ nilai perbedaanya tidak terlalu besar,bahkan mendekati sama. Salah satu masalah utama adalah pergeseran sudut pointing elektronik yang disebabkan oleh sistem mekanis yang kurang sempurna.

2. Dari hasil pengujian alat dalam melakukan pointing terhadap satelit PALAPA D, nilai ratarata total pointing manual yaitu signal strength 43,5\%, Signal Quality 59,5\%, BER $10^{-5,5}$, C/N 8,5 dB. Pointing elektronik dengan nilai rata-rata total yaitu signal strength 36\%, Signal Quality 40,9\%, BER $10^{-5,2}$ dan $C / N \quad 8,5$ dB. Maka dapat disimpulkan bahwa pointing manual lebih unggul dari pada pointing elektronik dari segi signal strength dan Signal Quality seperti pada pengujian Satelit TELKOM 1. Sedangkan nilai BER dan $C / N$ nilai perbedaanya tidak terlalu besar,bahkan mendekati sama.

3. Error yang terjadi pada nilai $A D C$ diakibatkan karena tingkat ketelitian potensiometer 5-30\% dan juga tingkat ketelitian konversi dari sinyal analog ke digital.

4. Besar pergerakan sudut azimuth yang dapat dibentuk oleh antena yaitu $50^{\circ}$, hal ini dipengaruhi oleh perbandingan sudut potensiometer dengan sudut sebenarnya yaitu ketika potensiometer berputar maksimal yaitu $300^{\circ}$, antena hanya dapat bergerak $50^{\circ}$ dan sudut elevai yang dapat dibentuk oleh antena yaitu $70^{\circ}$.

B. Saran

Adapun saran yang diberikan untuk perbaikan perancangan alat ini.

1. Penambahan modul GPS agar dalam penentuan lokasi dapat dilakukan secara otomatis.
2. Penambahan modul kompas dapat mengurangi kesalahan pada saat menentukan arah antena yaitu arah utara sebagai acuan $0^{\circ}$.

3. Penambahan satelit finder

Satelit finder berfungsi untuk mengkonversi sinyal dari satelit menjadi tegangan. Semakin bagus sinyal yang didapatkan maka nilai tegangan semakin besar. Satelit finder akan dihubungkan ke mikrokontroler sebagai sensor dalam menentukan pergerakan antena dengan memanfaatkan fungsi $A D C$ mikrokontroler. seperti halnya konversi pada penentuan sudut antena. Nilai tegangan yang didapat satelit finder akan diproses menggunakan $A D C$ pada mikro. Ketika mikrokontroler belum mendapatkan hasil yang maksimal maka mikro akan terus bekerja untuk menggerakkan motor.

\section{DAFTAR PUSTAKA}

[1] M. Imam and W. Pamungkas, Sistem Komunikasi Satelit Teori dan Praktik. Yogyakarta: CV Andi Offset, 2014.

[2] I.B. Harjayanti, "Analisis Jumlah Lnb Pada Sebuah Antena Parabola Terhadap Parameter Ber Pada Teknologi Dvb - S," Akademi Teknik Telekomunikasi Sandhy Putra Purwokerto, 2012.

[3] D. Roddy, Satellite communication 3rd. New York: Mcgraw Hill, 2001.

[4] H. Koppitz, "Apa itu LNB - dan untuk apa? in TELE-satellite International," Munich, Jerman, p. 12, 2006.

[5] W. Pamungkas, E. Wahyudi, and A. Nasuha, "Analisis Pengaruh Warna Antena Parabola Terhadap Parameter C/N Pada Aplikasi Dvb-S," in Semantik 2012, 2012.

[6] E. Safrianti, R. Amri, and Setiadi, "Aplikasi Atmega 8535 Dalam Pembuatan Alat Ukur Besar Sudut (Derajat)," J. Petir, vol. 5, no. 1, 2012.

[7] C. . Romadhon, "Sistem Keamanan Pintu Menggunakan Password Berbasis Mikrokontroler AT89S52," Palembang, 2010. 